\title{
ENFERMAGEM MATERNO-INFANTIL O SISTEMA DE ALOJAMENTO CONJUNTO PARA
RECÉM-NASCIDO E MÃE
}

\author{
Cândida Maria Cásar (Relatora) * \\ Cléa Dias Ribeiro ** \\ Marly Gay Calazans Damazo*** \\ Tereza Alkimin Silva ****
}

ReBEn/07

CASAR, C.M. e Colaboradoras - O Sistema de Alojamento Conjunto para Recém-Nascido e Mãe. Rev. Bras. Enf.; DF, 34 : 48-54, 1981.

\section{I — INTRODUÇÃO}

O relacionamento mãe-filho vem sendo um dos assuntos de maior destaque nos últimos anos e tem despertado a atenção dos profissionais da área de saúde para uma assistência integral ao RN, enfatizando as suas necessidades efetivas, o seu equilíbrio emocional e o processo de socialização.

Segundo Klaus e Kennell (1974), até o ano de 1880 os hospitais eram construídos sem berçário e o recém-nascido era colocado ao lado da mãe, que cuidava dele e o alimentava.

Dezesseis anos depois ocorreu a primeira mudança na assistência ao RN e à mãe, quando Martin Cooney utilizou a incubadora para o atendimento ao prematuro. Com isto, em quatro décadas, conseguiu a recuperação de 5.000 (cinco mil) RN, porém não permitia a participação da mãe nos cuidados prestados, a isto foi atribuída a dificuldade de aceitação pelos pais, do filho pré-tormo.

Nos anos de 1900, houve o isolamento mais estrito de todos os recém-nascidos, devido à alta mortalidade infantil ocorrida naquela época, tendo como causa a diarréia epidêmica, infecção respiratória e equipamentos inadequados.

Segundo a literatura, de 1945 a 1960, continuaram a recomendar o isolamento e a mínima manipulação do recémnascido, proibindo qualquer visita ao berçário, até mesmo da mãe.

Experiências em animais mostram (Klaus e Kennell - 1970) (Moore 1968) que, quando a mãe e o filhote são se-

* Enfermeira do Setor Alojamento Conjunto para RN e mãe da Mov.

* Assistente da Chefia do Serviço de Enfermagem da Mov.

*** Chefe do Serviço de Enfermagem da Mov.

**** Enfermeira da Unidade de Educação da Mov. 
CASAR, C.M. e Colaboradoras - O Sistema de Alojamento Conjunto para Recém-Nascido e Mãe. Rev. Bras. Enf.; DF, 34 : 48-54, 1981.

parados nas primeiras horas após o parto e são reunidos em seguida, a mãe apresenta distúrbios em seu comportamento, chegando mesmo a comer as filhotes.

Leifer e Col. (1972-1973), analisando vários estudos realizados em animais, sugerem que os processos de relacionamento mãe-filho no periodo pós-parto imediato são semelhantes em seres humanos. Após estes e outros estudos como Barnett (1970), marcaram o reinício da assistência conjunta mãe-filho (década de 1940).

A expressão Alojamento Conjunto (AC), traduzida do inglês "Roomingin", foi primeiramente empregada por Gesell e Ilg, em 1943, no seu livro "Infant and child in the Cul'ture of Today". Daí para cá, o sistema vem sendo largamente utilizado em inúmeros hospitais, numa tentativa de corrigir as desvantagens inerentes ao berçário convencional e que dizem respeito principalmente ao relacionamento humano mãe-filho-pai-parentes que foi completamen'te alterado pela localização do recém-nascido no berçário tradicional.

McBryde (1951) observou que o aleitamento materno aumentou de 35 para $58,5 \%$ após a instalação da unidade de "rooming-in", no Duke Hospital, relacionando a isto a proximidade do recém-nascido te a flexibilidade no horário, aumentando a lactação e favorecendo o peso do RN.

Montgomery (1949) afirma que a assistência de enfermagem no "roomingin" foi simplificada e as enfermeiras consideraram sua experiência neste sistema como uma oportunidade para praticar uma verdadeira enfermagem, devido ao método educacional do programa.

Embora a infecção tenha sido a causa principal da separação da mãe e filho, segundo Cox (1974), a infecção cruzada não constitui realmente um problema para este tipo de atendimento.

Para Montgomery, a vantagem do "rooming-in", no que concerne à infecção, é que a mesma se torna localizada em apenas um quarto, sendo possivel interditá-lo até que os RNs e mães do mesmo tenham alta.

Integrando-se a este sistema é que as enfermeiras da Maternidade Odete Valadares, contando com o apoio da Diretoria e demais profissionais, decidiram, em caráter experimental, implantar o Alojamento Conjunto para recémnascido e mãe, com a finalidade de:

- ministrar orientação adequada à mãe durante sua permanência no hospital, capacitando-a a cuidar integralmente do seu filho;

- estimular o aleitamento materno;

- reduzir a incidência de infecção no recém-nascido;

- reduzir o índice de rejeição da mãe ao recém-nascido.

\section{II - METODOLOGIA}

O estudo foi realizado na Maternidade Odete Valadares:

I - POPULAÇÃ:

A população foi constituída de clientes internadas na Maternidade Odete Valadares.

A mostra inclui as mães que receberam assistência de enfermagem no Setor de Alojamento Conjunto, no período de 28/03 a $31 / 08 / 1979$, num total de 210 (duzentos e dez) pacientes.

II - CRITERIOS PARA SELEÇAO DE AMOSTRAS:

Adotaram-se os seguinte critérios: 
CASAR, C.M. e Colaboradoras - O Sistema de Alojamento Conjunto para Recém-Nascido e Mãe. Rev. Bras. Enf.; DF, 34 : 48-54, 1981.

-- Clientes internadas na Unidade Campo de Pesquisa.

III - VARIÁVEIS:

Dependentes

- Educação primária

Independentes

- Idade;

- Estado Civil;

- Pré-Natal;

- Paridade.

IV - INSTRUMENTO DE COLETA:

Para coleta de dados foi utilizado formulário (anexo).

V - COLETA DE DADOS:

Os dados foram colhidos pelas enfermeiras da Maternidade Odete Valadares.

VI - ANALISE ESTATÍSTICA:

Os dados foram analisados através de tabelas.

\section{III - ORGANIZAÇÃO E FUNCIONA- MENTO}

Formou-se, inicialmente, um grupo de enfermeiras, para estudar a possibilidade de implantação do sistema na Maternidade Odete Valadares e, após discussão, elaborou-se um planejamento.

Área física : Adaptação de uma área no $2 .^{\circ}$ andar, ocupando 5 quartos com 2 camas e 2 berços em cada um, ante-sala com armários e mesas para roupas e materiais.

Pessoal Equipe multiprofissional.

Puérperas e Rns selecionados:
Mãe interessada

Primípara (de preferência)

RN a termo, hígido.

Tipo

Contínuo.

O RN, após 6 horas de vida, permanece ao lado da mãe.

Duração

72 horas.

Considerando o baixo nivel sócio-econômico-cultural da nossa clientela e o não comparecimento a um serviço de Pré-Natal, faz-se necessária esta permanência, para avaliação de sua aprendizagem.

Interrupção: Fatores maternos: infecções.

Problemas do RN: patologias graves.

Visitas

Número limitado (uma de cada vez, para cada paciente).

\section{ATENDIMENTO:}

A puérpera é admitida no A.C. logo após o parto e, 6 horas após, o RN é colocado no berço ao seu lado, quando se iniciam os cuidados com a participação progressiva da mãe.

De 1 a 6 horas de permanência do RN no A.C.:

- Estímulo ao aleitamento natural:

- Mãe recebe orientaçã̃o e observa us cuidados prestados ao RN e ajuda na hidratação oral.

No periodo de 6 a 12 horas de permanência no A.C.:

- A mãe participa dọs cuidados; 
CASAR, C.M. e Colaboradoras - O Sistema de Alojamento Conjunto para Recém-Nascido e Mãe. Rev. Bras. Enf.; DF, 34 : 48-54, 1981.

- Banho, peso, curativo umbilical, troca de roupa, estimulação psicomotora e hidratação oral.

De 12 a 24 horas de permanência no A.C.:

- A mãe passa a desempenhar os cuidados, sob a supervisão da enfermagem, sendo feita avaliação de sua aprendizagem, levando-se em consideração a habilidade de cada uma. As mães do Alojamento Conjunto recebem orientação grupal, onde são abordados conceitos de higiene, controle de saúde, importância do aleitamento materno, estimulação psicomotora e outros.

\section{IV - RESULTADOS E DISCUSSAO}

Tabela 1

\section{DISTRIBUIÇÃO DAS PUERPERAS, SEGUNDO A FAIXA ETARIA}

\begin{tabular}{|c|c|c|c|}
\hline Faixa & Etária & $\mathbf{F}$ & $\%$ \\
\hline - & 24 & 156 & 74,2 \\
\hline- & 34 & 45 & 21,5 \\
\hline $35-$ & 40 & 9 & 4,3 \\
\hline \multicolumn{2}{|c|}{ Total } & 210 & 100,0 \\
\hline
\end{tabular}

Observa-se, na tabela acima, que a maior percentagem $(74,2)$ de puérperas que são admitidas no A.C. está na faixa de 14 a 24 anos.

Tabela 2

DISTRIBUIÇÃO DAS PUÉRPERAS, SEGUNDO A PARIDADE

\begin{tabular}{crc}
\hline Paridade & F & $\%$ \\
\hline Primípara & 140 & 66,7 \\
Multipara & 70 & 33,3 \\
\hline Total & 210 & 100,0 \\
\hline
\end{tabular}

Verifica-se, na tabela 2, que o maior percentual $(66,7)$ de puérperas que vão para o A.C. são primíparas.

Tabela 3

DISTRIBUIÇÃO DAS PUÉRPERAS, SEGUNDO ESTADO CIVIL

\begin{tabular}{lrr}
\hline Estado Civil & F & $\%$ \\
\hline Solteira & 107 & 51,0 \\
Casada & 38 & 18,1 \\
Viúva & 1 & 0,5 \\
Vive c/o com- & 64 & 30,4 \\
panheiro & 210 & 100,0 \\
\hline \multicolumn{1}{c}{ Total } & \\
\hline
\end{tabular}

Verificando-se a tabela acima, podemos observar que as puérperas com estado civil, solteiras, atingem o maior percentual $(51,0)$ daquelas que são admitidas no A.C. da Maternidade Odete Valadares.

Tabela 4 RELAÇĀO ENTRE OS CUIDADOS E A APRENDIZAGEM

\begin{tabular}{|c|c|c|c|c|c|c|}
\hline \multirow{2}{*}{$\begin{array}{l}\text { Aprendizagem } \\
\text { Cuidados }\end{array}$} & \multicolumn{2}{|c|}{ Não sabia } & \multicolumn{2}{|c|}{ Sabia } & \multicolumn{2}{|c|}{ Total } \\
\hline & N. ${ }^{\circ}$ & $\%$ & N. ${ }^{\circ}$ & $\%$ & N. ${ }^{\circ}$ & 9 \\
\hline $\begin{array}{l}\text { Dar de mamar } \\
\text { Limpeza das mãos }\end{array}$ & 157 & 74,8 & 53 & 25,2 & 210 & 100,0 \\
\hline $\begin{array}{l}\text { e seios } \\
\text { Água filtrada e }\end{array}$ & 148 & 70,5 & 62 & 29,5 & 210 & 100,0 \\
\hline fervida & 102 & 48,6 & 108 & 51,4 & 210 & 100,0 \\
\hline Banho & 164 & 78,1 & 46 & 21,9 & 210 & 100,0 \\
\hline Curativo umbilical & 186 & 88,6 & 24 & 11,4 & 210 & 100,0 \\
\hline
\end{tabular}


Conforme tabela anterior, pode-se verificar que a coluna das puérperas que "não sabiam" executar os cuidados com - RN supera a das que "sabiam".

Verificou-se que $88,6 \%$ das mães não sabiam fazer o curativo umibilical e que o maior conhecimento é no uso da água filtrada e fervida.

\section{$\mathrm{v}$ - CONCLUSAO}

A entrevista realizada, individualmente, com as puérperas através da apiicação do formulário (anexo 1) permitiu as seguintes conclusões:

- O Sistema Alojamento Conjunto, para Recém-Nascido e Mãe, propicia a sua clientela oportunidade de aprendizagem quanto aos cuidados com o $\mathrm{RN}$, através de orientação individual e grupal, ministrada pela equipe de enfermagem;

- Oferece ao binômio Māe-Filho um relacionamento mais precoce do que o tradicional berçário $\theta$ incentiva 0 aleitamento materno.

\section{VI - RESUMO}

As autoras relatam uma experiência na organização do "Sistema Alojamento Conjunto para Recém-Nascido $\theta$ Mãe" na Maternidade Odete Valadares em Belo Horizonte.

$\mathrm{Na}$ implantação desse sistema, as enfermeiras tiveram os seguintes objetivos:

- ministrar orientação adequada à mãe durante sua permanência no hospital, capacitando-a a cuidar integralmente do seu filho;

- estimular o aleitamento materno;

- reduzir a incidência de infecção no Recém-Nascido;

- reduzir o índice đe rejeição da mãe ao Recém-Nascido.
O trabalho desenvolvido na Unidade proporciona à sua clientela oportunidade de aprendizagem, considerando que o maior percentual de puérperas admitidas são primíparas e que, do ponto de vista de Educação para a Saúde, é o grupo prioritário, visando à desmistificação de tabus.

\section{SUMMARY}

The authors relate an experience in the organization of the System "A Place beside the Mother for the Newly Born Baby" in the Maternity Hospital "Odete Valadares", Belo Horizonte.

In the implantation of this system are the following objectives:

- To minister orientation adequate for the mother during her stay in the hospital, thus capacitating the mother in the COMPLETE CARE of her child;

- To stimulate maternal milke;

- Reduce the incidence of infection in the NEW BORN BABY;

- Reduce the incidente of rejection by the mother ,to the New Born Baby.

The work desenvolved in the UNIT, proportions for the patients a greater opportunity to learn, considering that $\mathrm{t} h \mathrm{e}$ greater percentage of patients admitted are primiparas and that, from the point of view of Education for Health reason, is the priority group, seeing the possibility of putting aside MISUNDERSTANDING.

\section{VII - RECOMENDAÇÕES}

Tendo em vista o resultado obtido através deste trabalho, recomenda-se que:

1 - Os profissionais da área de saúde voltem sua atenção para o "Sistema de Alojamento Conjunto para Recém-Nascido e Mãe". 
CASAR, C.M. e Colaboradoras - O Sistema de Alojamento Conjunto para Recém-Nascıdo e Mãe. Rev. Bras. Enf.; DF, 34 : 48-54, 1981.

2 - Os enfermeiros incentivem as mães a permanecerem na Maternidade ao lado do filho.

3 - Os enfermeiros enfatizem a importância do Alojamento Conjunto às gestantes no Pré-Natal.

4 - Os serviços de enfermagem elaborem programas educativos e pro- movam treinamentos com o pessoal, para atuar em Unidade de Alojamento Conjunto.

5 - As escolas de enfermagem enfatizem a atuação do estudante nis ařea preventiva do programa $\mathbf{M a}$. terno-Infantil, focalizando a inte. ração recém-nascido/mãe.

B I B L I O R A F I A

1. HARUNARI, L. ....... O Sistema Alojamento Conjunto para Recém-nascido e Mãe em Maternidade ou em Unidade Obstétrica como contribuição para a assistência integral ao RecémNascido, Porto Alegre, 1976.

2. SEGRE, C. A. M. "et alli" ....... Cuidados ao Recém-Nascido em Alojamento Conjunto. ..............

3. SEGRE, C. A. M. "et alli" - Alojamento Conjunto Mãe-Recém-Nascido na Maternidade Escola de Vila Nova Cachoeirinha - Maternidade e Infância (Arquivos Médicos - Sociais) Órgão da L.B.A., 1 (36) : 24-43 Jan/ mar., 1977.

4. ....... Aleitaments Materno - Novos ângulos para uma questão antiga. Atualidades Médicas; 17-22, mar/79.
5. AUGUSTO, M. ........ Alojamento Conjunto, Escola Paulista de Enfermagem, Departamento de Enfermagem Pediátrica, São Paulo, 1977, Mimeo.

6. LEBOYER, F. ........ Nascer Sorrindo - 2. ${ }^{a}$ ed. Editora Brasiliense, 1978.

7. ........ Ministério da Saúde, Unidade de Berçário, Diário Oficial; Seção I - Parte I - Dezembro, 1967.

8. BOSIO, B. ......; AMARAL, I. T. ....; CASTRO, P. ........ O Sistema Alojamento Conjunto mãe e rn nas Maternidades. Trabalho de Conclusão de Curso de Especialização em Pediatria e Puericultura da Escola Paulista de Enfermagem, São Paulo, .... 1976, Mimeo.

\section{MATERNIDADE ODETE VALADARES}

\section{FORMULÁRIO (ANEXO 1)}

Opinião das mães que participaram do "Sistema Alojamento Conjunto" na Maternidade Odete Valadares.

\section{IDENTIFICAÇÃO}

\section{NOME}

REGISTRO N. ${ }^{\circ}$

\begin{abstract}
ESTADO CIVIL: Casada Vive c/companheiro
\end{abstract}

COR: Branca

IDADE

ESCOLARIDADE: Analfabeta ( ) Prim. Incompleto

FEZ PRE-NATAL:

$\begin{array}{llll}\text { ( ) } & \text { Viúva ( ) } & \begin{array}{l}\text { Solteira ( ) } \\ \text { ( ) }\end{array} & \\ \text { ( ) } & \text { Preta ( ) } & \text { Morena ( ) }\end{array}$

PROFISSÃO

Primário Completo

( )

Looal 
CASAR, C.M. e Colaboradoras - O Sistema de Alojamento Conjunto para Recém-Nascido e Mãe. Rev. Bras. Enf.; DF, 34 : 48-54, 1981.

RECÉM-NASCIDO

$\begin{array}{lllll}\text { SEXO: Masculino } & \text { ( ) } & & \text { Feminino ( ) } \\ \text { COR: Branca } & \text { ( ) } & \text { Preta ( ) } & \text { Morena ( ) } \\ \text { PESO: Nascimento } & & \text { Alta } & \end{array}$

CLASSIFICAÇĀO DO A.C.

$\begin{array}{lll}\text { ALOJAMENTO CONJUNTO: } & \text { Completo } & (\text { ) } \\ & \text { Interrompido } & (\text { ) } \\ & & \\ \text { INTERCORRENCIAS: } & \text { Icterícia } & (\text { ) } \\ & \text { Impetigo } & (\text { ) } \\ & \text { Diarréia } & (\text { ) } \\ & \text { Outros } & (\text { especificar }\end{array}$

OBSERVAÇOEES:

1 - PARIDADE: ( )

2 - ANESTESIA: Local ( ) Peridural ( )

3 - N. ${ }^{\circ}$ de PARTOS EM HOSPITAL: ( )

Geral ( ) Raque ( )

4 - N. ${ }^{\circ}$ de PARTOS NO DOMICÍLIO: ( )

5 - O que você sentiu quando soube que ia ganhar este filho?

Feliz ( )

Infeliz ( )

Indiferente ( )

POR QUÊ?

6 - Algumas mães gostam de ter o filho no quarto junto com elas, outras gostam que ele fique no berçário, o que você acha?

- Gostou de ter o filho no quarto junito com você

- Gostaria que o filho ficasse no bercário

- Não respondeu

7 - O que achou do modo como a equipe de enfermagem cuidou de você e de seu filho?

Gostou ( ) Não gostou ( ) Não respondeu ( )

POR QUE?

8 - O que você aprendeu no A.C.?

- Dar de mamar

- Limpeza de mãos e seios

$\operatorname{Sim}($ )

Não ( )

- Vestir o bebê

$\operatorname{Sim}()$

Não ( )

- Limpeza do bebē

$\operatorname{Sim}(\quad)$

Não ( ) )

- Dar água fervida ao bebê

$\operatorname{Sim}($ )

Não ( )

- Curativo umbilical

$\operatorname{Sim}($ )

Não ( )

9 - Que mais você gostaria de ter aprendido?

Não ( )

10 - Gostou de ter menos visita? Sim ( )

Não ( )

11 - OBSERVAÇOES:

Não respondeu

() 